\title{
Relation of fingerprints and shape of the palm to fetal growth and adult blood pressure
}

\author{
K M Godfrey, D J P Barker, J Peace, J Cloke, C Osmond
}

\author{
Abstract \\ Objective-To examine how finger and palm \\ prints are related to fetal growth and adult blood \\ pressure.
}

Design-Follow up study of babies born around 50 years ago whose birth weight, placental weight, head circumference, and length at birth were recorded.

Setting-Preston, Lancashire.

Subjects-139 men and women born in Sharoe Green Hospital in Preston during 1935-43 and still living in Lancashire.

Main outcome measures-Finger and palm prints and current blood pressure.

Results-People who were thin at birth had more whorl patterns on their fingers. People who were short at birth in relation to their head circumference had longer hands and a narrower palmar angle. Mean systolic blood presure was $8 \mathrm{~mm} \mathrm{Hg}$ higher ( $95 \%$ confidence interval 2 to $13 ; p=0.01$ ) in the 93 men and women with a whorl pattern on one or more fingers compared with the 46 who had no whorls. The greater the number of fingers with whorls the higher the systolic blood pressure. Whorls on the right hand were more strongly associated with higher systolic pressure than whorls on the left, mean systolic pressure rising by $2 \cdot 2 \mathrm{~mm} \mathrm{Hg}(0.2$ to $4 \cdot 1$; $p=0.03$ ) for each additional whorl on the right hand. People with long hands and a narrow palmar angle also had higher systolic pressure. Again, these associations were stronger for the right hand. Mean systolic pressure rose by $0.49 \mathrm{~mm} \mathrm{Hg}(-0.03$ to 1.01 ; $p=0.06$ ) for each degree decrease in palmar angle on the right hand.

Conclusions-Fingertip whorls and a narrow palmar angle are indelible markers of impaired fetal development at different stages in pregnancy. Both are associated with raised blood pressure in adult life.

Epidemiology Unit,

University of

Southampton,

Southampton General

Hospital, Southampton SO9 4XY

K M Godfrey, Medical Research Council training fellow

D J P Barker, director

$\mathrm{J}$ Peace, research assistant

C Osmond, statistician

Fingerprint Section, Scenes of Crime Department, Victoria Block, New Scotland Yard, London SW1

J Cloke, senior fingerprint expert

Correspondence to: Dr Godfrey.

BMF 1993;307:405-9

\section{Introduction}

Babies who are small at birth tend to develop high blood pressure as adults. ${ }^{1-4} \mathrm{~A}$ recent study identified two groups of babies, born at term, who later had high blood pressure. ${ }^{5}$ One group was thin at birth, as measured by a low ponderal index (birth weight/ length ${ }^{3}$ and had below average birth weight and placental weight. The other group was short at birth in relation to the head circumference but had average birth weight and above average placental weight. The differences in these two groups are thought to result from fetal undernutrition at different stages of gestation.

The dermal ridges of the fingers and palm are markers for patterns of fetal growth. The patterns formed by the dermal ridges reflect growth and development during early gestation and are determined by the 19 th week. ${ }^{-8}$ As the finger pads develop a series of dermal ridges are formed. The ridges are related to the shape of the finger pad and come to resemble contour lines around a hill. Swollen finger pads induce a complex "whorl" pattern of ridges, whereas flat pads become covered by a simple "arch" pattern or a pattern of intermediate complexity known as a "loop." ${ }^{8}$ Palm prints can be used to assess the length of the palm of the hand relative to its breadth by measuring the so called palmar atd angle between specific points at the wrist and the bases of the fore and little fingers. ${ }^{8}$ Little is known about either the time when the shape of the palm of the hand is established or about differences in finger and palm dermatoglyphics in babies who had different forms of intrauterine growth retardation. The different finger and palm prints of identical twins with separate placentas suggests that they are not primarily genetically determined. ${ }^{\text {The }}$ abnormal finger and palm prints of people with congenital rubella support this. ${ }^{10}$

Two studies in India showed that people with hypertension had abnormal dermatoglyphics. ${ }^{112}$ In comparison with controls they had more whorls and palms that were relatively long compared with their breadth, especially on the right hand. A study of American Japanese in Hawaii similarly showed that men who had had a myocardial infarction had more whorls on their fingers, again especially on the right hand. ${ }^{13} \mathrm{~A}$ large series of fingerprints of the British population showed that whorls are commoner on the right hand. ${ }^{14}$

We studied whether fingerprint patterns and the shape of the palm of the hand reflect specific patterns of fetal growth, as indicated by measurements at birth, and whether they are related to adult blood pressure in the general population. Demonstration of such associations would give an insight into the time in gestation when hypertension is initiated and the mechanisms which underlie it.

\section{Subjects and methods}

As we have previously described ${ }^{1}$ unusually complete and detailed records from the labour ward were kept on all babies delivered at Sharoe Green Hospital in Preston from 1934 onwards. The record included the date of the mother's last menstrual period and the baby's birth weight, placental weight, crown-heel length, and head circumference. Weights were measured in pounds ( 1 pound $=454 \mathrm{~g}$ ) and length and head circumference in inches $(1$ inch $=2.54 \mathrm{~cm}$ ). Measurements were often rounded, and we therefore preserved the original units.

We used the NHS central register to trace the 1298 singleton infants born in the hospital during 1935-43. A total of 503 were found to be living in Lancashire at addresses known to their general practitioner, and 449 took part in our initial study. We asked 402 to take part in a second study, which involved coming to a clinic in Preston ${ }^{2}$ but we did not 
think it appropriate to ask these people to take part in another study. We therefore approached the 47 people who were not asked to take part in the second study because they lived too far from Preston and 131 others who had been traced only recently and did not take part in our initial study. Ten of the 178 people could not be contacted at their last known address and 29 declined to take part, leaving 139 who took part.

Each person was visited at home by a single fieldworker (JP), who had not seen the obstetric records. The people were asked about their consumption of alcohol, which was categorised as low, moderate, or high as in the previous study. ${ }^{1}$ The subject's social class at birth was classified from their father's occupation and their current social class from their own or their husband's occupation. Height was measured with a portable stadiometer and weight with a portable Seca scale. Blood pressure was measured with an automated recorder (Dinamap) when the subjects were seated. Previous validation has shown mean blood pressures measured with a Hawksley random zero sphygmomanometer and a Dinamap to be closely similar. Readings were taken on the left arm with the cuff size recommended for the arm circumference. Two readings were taken at an interval of 5 minutes, and the mean value was used in the analysis.

Rolled fingerprints and palm prints were obtained by placing the palm and digits on an inked plate and then rolling them on to a record form. Fingerprint ink was used to obtain high quality prints. The pattern on each finger was coded by a senior scenes of crime fingerprint expert at Scotland Yard (JC), who had no knowledge of the obstetric data or recordings of blood pressure. Each code was checked by a second fingerprint expert from Scotland Yard.

Each finger was classified as having a pattern of one of three main types: arches, loops, or whorls. This classification is based on the number of points, called triradii, where three ridge systems meet (fig 1)..$^{814}$ Arches have no triradius, loops have one, and whorls have two. The absolute ridge count was determined as the sum for all 10 fingers of the number of ridges between the centre of a loop or whorl and the single triradius for a loop and the two triradii for a whorl. ${ }^{813}$ This reflects the size and number of whorls. Three digits had been amputated and two had cuts or permanent scars. In accordance with convention ${ }^{14}$ for statistical analyses these were assigned the pattern code and ridge count of the medial neighbouring digit. The angle between the $a, t$, and $d$ triradii on the palm of the hand (atd angle) and the component $a d$, at, and $d t$ distances were measured directly from the prints (fig 2). In two subjects incomplete palm prints precluded determination of the atd angle, and in another a print could not be taken because of palmar lacerations.

The study was approved by the Preston ethics committee. Statistical analysis was by multiple regression and tabulation of means. Men had a mean systolic pressure $7.7 \mathrm{~mm} \mathrm{Hg}$ higher and a mean diastolic

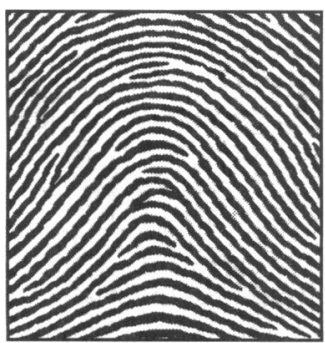

Arch (no triradius)

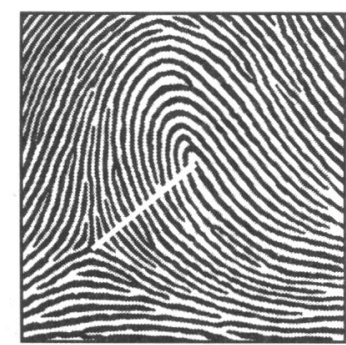

Loop (one triradius)

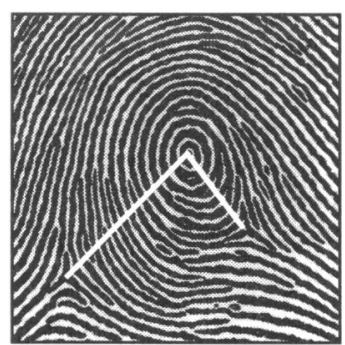

Whorl (two triradii)
FIG 1-Examples of three basic types of fingerprint patterm. Lines join centre of pattern with triradii where three ridge systems meet. Number of ridges cutting line(s) constitutes ridge count (in these examples, 13 for loop and 25 for whorl). Reproduced with permission from Holt $S$. Quantitative genetics of fingerprint patterns. "Br Med Bull" 1961;17:247

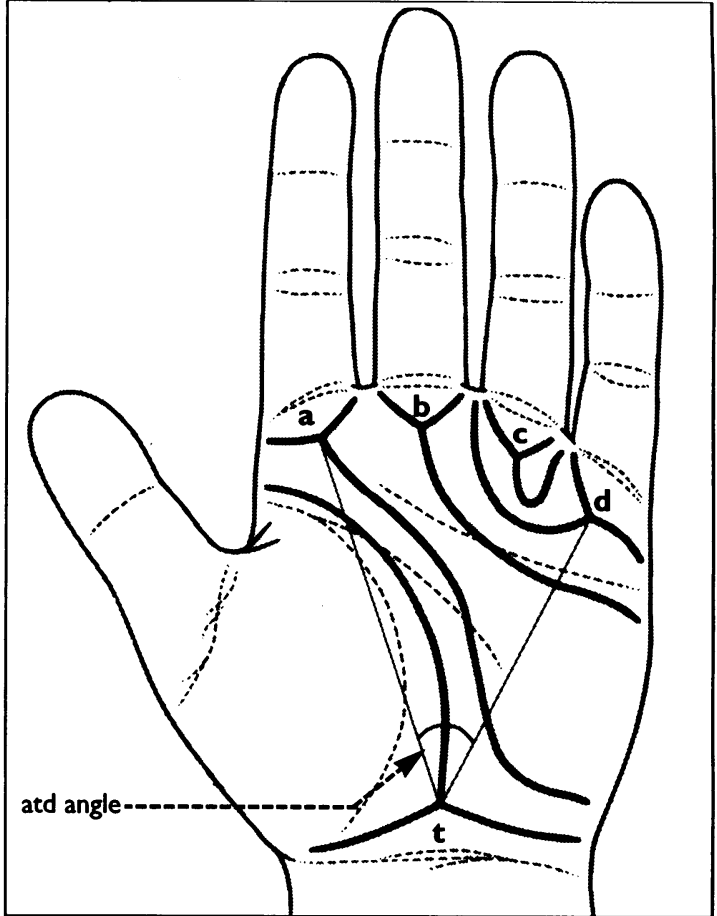

FIG 2-Location of major palmar triradii $(a, b, c, d$, and $t)$ indicating palmar atd angle

pressure $9.8 \mathrm{~mm} \mathrm{Hg}$ higher than women. Blood pressures were therefore adjusted for sex by regression. Blood pressure was not related to current age within the narrow age range of people studied.

\section{Results}

DERMATOGLYPHICS AND ADULT BLOOD PRESSURE

The mean (SD) systolic pressure for all subjects was 141 (17) $\mathrm{mm} \mathrm{Hg}$. Mean systolic blood pressure was $144 \mathrm{~mm} \mathrm{Hg}$ in the 93 subjects with a whorl on one or more fingers compared with $136 \mathrm{~mm} \mathrm{Hg}$ in the 46 subjects who had no whorls on any finger (difference $8 \mathrm{~mm} \mathrm{Hg} ; 95 \%$ confidence interval 2 to $13 ; \mathrm{p}=0.01)$. Table I shows the mean systolic pressure according to fingerprint pattern on each of the 10 fingers. For each

TABLE I-Mean systolic blood pressure ( $\mathrm{mm} \mathrm{Hg}$ ) in 139 men and women aged 47-56 years according to fingerprint pattern on each finger. Numbers of subjects in parentheses

\begin{tabular}{lccc}
\hline & \multicolumn{3}{c}{ Dermatoglyphic pattern } \\
\cline { 2 - 4 } Digit & Arch & Loop & Whorl \\
\hline Right hand: & & & \\
Thumb & $140(2)$ & $141(95)$ & $143(42)$ \\
Fore & $136(20)$ & $140(72)$ & $146(47)$ \\
Middle & $136(9)$ & $140(109)$ & $150(21)$ \\
Ring & $129(2)$ & $139(72)$ & $144(65)$ \\
Little & $140(4)$ & $142(114)$ & $141(21)$ \\
Left hand: & $143(5)$ & $140(91)$ & $145(43)$ \\
Thumb & $139(19)$ & $141(78)$ & $143(42)$ \\
Fore & $135(12)$ & $142(108)$ & $143(19)$ \\
Middle & $139(7)$ & $140(83)$ & $145(49)$ \\
Ring & $146(6)$ & $141(114)$ & $144(19)$ \\
Little & & &
\end{tabular}

finger, apart from the little finger, subjects who had a whorl pattern had the highest pressure. Systolic pressure rose as the number of fingers with whorls increased, rising by $1.1 \mathrm{~mm} \mathrm{Hg}(0.0$ to $2 \cdot 1 ; \mathrm{p}=0.04)$ for each additional finger. There were 196 whorls on the fingers of the right hand compared with 172 on the left. Systolic pressure rose by $2.2 \mathrm{~mm} \mathrm{Hg}(0.2$ to $4 \cdot 1$; $\mathrm{p}=0.03$ ) for each additional whorl on the right hand and by $1.7 \mathrm{~mm} \mathrm{Hg}(-0.3$ to $3.7 ; \mathrm{p}=0.1)$ for each additional whorl on the left hand.

The mean absolute ridge count was 168 (76). Consistent with the association between whorls and 
systolic blood pressure, mean systolic pressure rose by $0.37 \mathrm{~mm} \mathrm{Hg}$ for every increase of 10 in ridge count $(0.00$ to $0.74 ; p=0.05)$. The ridge count on the right hand was more strongly associated with systolic pressure than the ridge count for all 10 fingers. Systolic pressure rose by $0.88 \mathrm{~mm} \mathrm{Hg}(0.17$ to $1.60 ; \mathrm{p}=0.02)$ for every increase of $10 \mathrm{in}$ ridge count on the right hand and by $0.53 \mathrm{~mm} \mathrm{Hg}(-0.19$ to 1.25$)$ for every increase of 10 in ridge count on the left hand.

The mean palmar atd angle was 41.7 (5.5) degrees. Palmar angle was unrelated to the total number of whorls or the absolute ridge count. Systolic pressure rose by $0.49 \mathrm{~mm} \mathrm{Hg}(-0.03$ to $1.01 ; \mathrm{p}=0.06)$ for each degree decrease in atd angle on the right hand and by $0.31 \mathrm{~mm} \mathrm{Hg}(-0.21$ to $0.83 ; \mathrm{p}=0.2)$ for each degree decrease on the left hand.

Table II shows mean systolic pressure according to the atd angle and number of whorls on the right hand. The highest mean pressures occurred in subjects with an atd angle of $42^{\circ}$ or less and three or more whorls on the right hand. Regression analysis of the relation between blood pressure and the component $d t$, at, and $a d$ measurements that determine the atd angle of the right hand showed that systolic pressure increased with greater length of the palm, measured by the distances $d t \quad(\mathrm{p}=0.02)$ and at $(\mathrm{p}=0.18)$, but was unrelated to the breadth of the palm, ad $(\mathrm{p}=0.9)$. Whereas atd angle was unrelated to adult height, the $d t, a t$, and ad distances were all strongly related to adult height $(p \leqslant 0.005)$. The relations between $d t$ and at lengths and adult blood pressure were, however, independent of adult height and, if anything, were stronger after regression adjustment for height.

The mean diastolic pressure was 81 (10) $\mathrm{mm} \mathrm{Hg}$. The trends in diastolic pressure with the total number of whorls $(p=0.02)$, the absolute ridge count $(p=0.02)$, and the palmar angle $(p=0.08)$ on the right hand were similar to those with systolic pressure.

There were no significant differences in the absolute ridge count or the number of whorls and the atd angle on the right hand between men and women or with social class at birth or current social class and smoking habits (table III). Likewise, they were unrelated to current body mass index (weight/height ${ }^{2}$ ). Dermato-

TABLE II-Mean systolic blood pressure $(\mathrm{mm} \mathrm{Hg})$ in 136 men and women aged 47-56 years according to palmar "atd" angle and fingerprint patterns on the right hand. Numbers of subjects in parentheses

\begin{tabular}{lcccc}
\hline & \multicolumn{5}{c}{ Total No of whorls } \\
\cline { 2 - 5 } Palmar atd angle (degrees) & 0 & $1-2$ & $3-5$ & All \\
\hline$\leqslant 39$ & $142(15)$ & $145(17)$ & $148(13)$ & $145(45)$ \\
$40-42$ & $136(19)$ & $143(17)$ & $148(11)$ & $141(47)$ \\
$\geqslant 43$ & $137(16)$ & $141(17)$ & $139(11)$ & $139(44)$ \\
\hline All & $138(50)$ & $143(51)$ & $145(35)$ & $142(136)$ \\
\hline
\end{tabular}

${ }^{\star}$ Could not be determined in three subjects.

TABLE III-Mean absolute ridge count and number of whorls and "atd" angle on right hand of 139 men and women aged 47-56 according to social class at birth and current social class and smoking habit

\begin{tabular}{|c|c|c|c|c|}
\hline Variable & $\begin{array}{l}\text { Absolute } \\
\text { ridge } \\
\text { count }\end{array}$ & $\begin{array}{l}\text { No of } \\
\text { whorls on } \\
\text { right hand }\end{array}$ & $\begin{array}{l}\text { atd Angle } \\
\text { on on } \\
\text { right hand }\end{array}$ & $\begin{array}{c}\text { No of } \\
\text { subjects }\end{array}$ \\
\hline \multicolumn{5}{|l|}{ Social class at birth^: } \\
\hline I, II, III Non-manual & 148 & $1 \cdot 0$ & $41 \cdot 3$ & 33 \\
\hline III Manual & 184 & $1 \cdot 7$ & $41 \cdot 6$ & 57 \\
\hline IV, V & 164 & $1 \cdot 3$ & $42 \cdot 1$ & 39 \\
\hline \multicolumn{5}{|l|}{ Current social classt: } \\
\hline I, II, III Non-manual & 173 & 1.5 & $41 \cdot 8$ & 72 \\
\hline III Manual & 166 & $1 \cdot 2$ & $41 \cdot 4$ & 34 \\
\hline IV, V & 168 & 1.5 & $41 \cdot 6$ & 31 \\
\hline \multicolumn{5}{|l|}{ Smoking habits: } \\
\hline Never smoked & 174 & 1.5 & 42.5 & 40 \\
\hline Former smoker & 168 & 1.5 & 40.9 & 46 \\
\hline Current smoker & 164 & $1 \cdot 3$ & $41 \cdot 8$ & 53 \\
\hline
\end{tabular}

*Could not be determined in 10 subjects.

tCould not be determined in two subjects.
TABLE IV-Mean absolute ridge count of 123 men and women aged 47-56 born after 38 completed weeks of gestation according to placental weight and ponderal index at birth. Numbers of subjects in parentheses

\begin{tabular}{|c|c|c|c|c|c|}
\hline \multirow{2}{*}{$\begin{array}{l}\text { Placental weight } \\
\text { (pounds) }^{\star}\end{array}$} & \multicolumn{5}{|c|}{ Ponderal index (ounces $/$ inch $\left.^{3} \times 1000\right) \dagger$} \\
\hline & $\leqslant 12$ & $-13 \cdot 25$ & $-14 \cdot 75$ & $>14.75$ & All \\
\hline$\leqslant 1 \cdot 25$ & $204(15)$ & $173(18)$ & $164(20)$ & $121(15)$ & $166(68)$ \\
\hline$>1.25$ & $188(7)$ & $150(10)$ & $159(24)$ & $197(14)$ & 171 (55) \\
\hline All & $199(22)$ & $164(28)$ & $161(44)$ & $158(29)$ & $168(123)$ \\
\hline
\end{tabular}

*1 Pound $=454 \mathrm{~g} . \quad+1$ Ounce $=28 \mathrm{~g}, 1 \mathrm{inch}=2.54 \mathrm{~cm}$.

TABLE V-Mean palmar atd angle of 120 men and women * aged 47-56 born after 38 completed weeks of gestation according to placental weight and head circumference at birth. Numbers of subjects in parentheses

\begin{tabular}{|c|c|c|c|c|c|}
\hline \multirow{2}{*}{$\begin{array}{l}\text { Placental weight } \\
\text { (pounds } \dagger \text { ) }\end{array}$} & \multicolumn{5}{|c|}{ Head circumference at birth (inches) $\ddagger$} \\
\hline & $\leqslant 13.25$ & $-13 \cdot 75$ & $-14 \cdot 0$ & $>14.0$ & All \\
\hline $\begin{array}{l}\leqslant 1.25 \\
>1.25\end{array}$ & $\begin{array}{l}40 \cdot 8(27) \\
43.3(9)\end{array}$ & $\begin{array}{l}40 \cdot 9(18) \\
42 \cdot 4(11)\end{array}$ & $\begin{array}{l}43 \cdot 3(18) \\
41.6(23)\end{array}$ & $\begin{array}{l}42 \cdot 2 \quad(5) \\
40 \cdot 2 \quad(9)\end{array}$ & $\begin{array}{ll}41 \cdot 6 & (68) \\
41 \cdot 8 & (52)\end{array}$ \\
\hline All & $41 \cdot 4(36)$ & $41 \cdot 4(29)$ & $42 \cdot 3(41)$ & $40.9(14)$ & $41 \cdot 7(120)$ \\
\hline
\end{tabular}

${ }^{\star}$ Could not be determined in three subjects.

†1 Pound $=454 \mathrm{~g}$.

$\ddagger 1$ Inch $=2.54 \mathrm{~cm}$

glyphics were similarly related to systolic pressure in men and women and in each social class. Similar to the results from the previous study in Preston, people with higher body mass indices had increased systolic pressure. Adjusting for body mass index by regression made little difference to the values in tables I and II. Mean systolic pressure was unrelated to alcohol intake within these subjects.

SIMULTANEOUS ANALYSIS OF BLOOD PRESSURE WITH BIRTH MEASUREMENTS AND DERMATOGLYPHICS

Consistent with the results from previous studies mean systolic pressure tended to be higher in people with lower birth weight (by $1.3 \mathrm{~mm} \mathrm{Hg}$ per pound (454 g) of birth weight; -1.7 to $4 \cdot 2$ ) and to be higher in people whose placental weight was above 1.5 pounds (681 g) (by $4.4 \mathrm{~mm} \mathrm{Hg} ;-3.7$ to 12.5 ), though these relations were not significant in this small population. In simultaneous regressions of adult systolic pressure in relation to dermatoglyphics and placental weight and birth weight, a greater number of whorls $(p=0.04)$ and a narrower atd angle $(\mathrm{p}=0.06)$ on the right hand were more strongly associated with higher pressure than were placental or birth weights.

DERMATOGLYPHICS AND BIRTH MEASUREMENTS

As the proportionate relations of birth weight, length, head circumference, and placental weight differ in babies born prematurely we followed the procedure of our previous study of birth measurements ${ }^{5}$ and restricted these analyses to the 123 men and women born after 38 completed weeks ( 266 days) of gestation. Neither birth weight, placental weight, length, or head circumference at birth were significantly associated with the number of whorls, the absolute ridge count, or the palmar atd angle. In the same way as in our study of blood pressure 5 we next analysed these relations within two groups according to placental weight, dividing the subjects around the median placental weight $(1 \cdot 25$ pounds $(568 \mathrm{~g}))$.

Among people whose placental weight was 1.25 pounds or less those who had lower birth weight had more whorls and a higher ridge count. In contrast, those who were long at birth also had more whorls and a higher ridge count. In a simultaneous multiple regression analysis, both lower birth weight and greater length were significantly associated with a higher ridge count $(p=0.02$ and 0.05 , respectively). We used the ponderal index (birth weight/length ${ }^{3}$ ) as a measure of thinness. Table IV uses the same divisions of ponderal index as in our previous study. It shows 
that mean absolute ridge count fell progressively from 204 to 121 between people with a ponderal index of 12 or less and those with a ponderal index of more than 14.75. Regression analysis showed that the absolute ridge count fell by 14 ( 3 to $25 ; p=0.02$ ) for each unit increase in ponderal index. At placental weights above 1.25 pounds the number of whorls and the ridge count were unrelated to any birth measurement.

Among people whose placental weight was 1.25 pounds or less, palmar atd angle was not related to birth measurements. At placental weights above 1.25 pounds, however, the palmar angle was narrower in people with a large head circumference. In a simultaneous analysis with the other birth measurements the trend with head circumference was strongly significant $(p=0.004)$. There was no similar trend between length or weight and palmar angle. Table $\mathrm{V}$ uses the same divisions of head circumference as in our previous study. It shows that mean palmar atd angle fell progressively from $43.3^{\circ}$ to $40.2^{\circ}$ between people with a head circumference of 13.25 inches $(33.7$ $\mathrm{cm})$ or less and those with a head circumference of more than 14 inches $(35.6 \mathrm{~cm})(p=0.05)$. Similarly, there was a fall in palmar angle with increasing ratio of head circumference to length at birth, though this was not significant.

\section{Discussion}

We have shown that fingerprint patterns and the palmar atd angle in men and women are associated with blood pressure. People with a whorl on one or more fingers had raised blood pressure in adult life. We found that whorls were more common on the fingers of the right hand, a finding previously recorded by the police in a large survey in Britain. ${ }^{14}$ The association with blood pressure was stronger for whorls on the right hand than the left. Long hands relative to their breadth and a narrow palmar atd angle were independently associated with raised adult blood pressure. Again these associations were stronger for the right hand. Associations between fingerprint patterns, palmar atd angle, and blood pressure within the normal range have not been shown before. Our findings are consistent with those of two studies in India, which showed that patients with hypertension tended to have more finger whorls and narrower palmar angles, especially on the right hand..$^{112}$

The people we studied were born in hospital in Preston and had either stayed in the town or moved to other parts of Lancashire. Although they were not a random sample of births, our analysis was based on internal comparisons, and the selection of the sample would introduce bias only if the relations between finger and palm prints, fetal growth, and blood pressure differed in those selected and not selected. This is unlikely. There was no relation between finger and palm prints and social class or smoking and the relation between finger and palm prints and raised blood pressure was independent of adult body mass index and present in each social class.

We have also shown a relation between whorls and a narrow palmar atd angle and two patterns of fetal growth previously shown to be associated with higher adult blood pressure. ${ }^{5}$ Men and women born at term who were thin at birth and had placental weights below the median tended to have more finger whorls and a higher ridge count. Those who were short at birth in relation to their head size and had a placental weight above the median tended to have narrower palmar atd angles. To our knowledge these relations have not been described before. They raise fundamental questions about the genesis of the dermal ridge patterns of the fingertips and what determines the length of the human hand relative to its breadth.

\section{Epidemiological implications}

- Fingertip whorls and a narrow palmar angle are indelible markers of impaired fetal development at different stages in pregnancy

- Fingerprint whorls reflect impaired growth and development during early gestation and are determined by the 19 th week

- Both fingertip whorls and a narrow palmar angle are associated with high blood pressure in adult life

- This is further evidence that raised adult blood pressure originates in utero

The patterns formed by a series of ridges over the elevations of the early embryonic finger pads are determined by the shape of the elevation at the critical time between 13 and 19 weeks' gestation, when ridges develop. ${ }^{6}$ Patterns are formed like contour lines around a hill with the centre of a pattern corresponding to the peak of the hill. Mathematical considerations dictate that parallel ridges stretching over a more bulbous finger pad will form whorls rather than simpler arch or loop patterns. In contrast, the flattest finger pads will be covered by arches. Bulbous finger tips and hence whorls are associated with oedema of the fingertip, as in Turner's syndrome, ${ }^{8}$ and with either rapid growth or delayed regression of the fetal digital pads. ${ }^{6}$

Hypertension induced by catecholamines in fetal lambs results in generalised oedema. ${ }^{15}$ One possible explanation for our findings is that whorl formation may reflect fingertip oedema as a direct result of higher fetal blood pressure in early pregnancy. Alternatively, it may be linked to vascular supply, which is a key determinant of fetal limb growth. Arteriovenous malformations, as in the Parkes-Weber syndrome, or surgically induced arteriovenous fistulae, which increase the blood supply to a limb, are associated with hypertrophy of all the structures in the limb. ${ }^{1617}$ Whorl development may reflect increased growth of the finger pads associated with relatively high blood flow in the fetal arms in early pregnancy.

The higher prevalence of whorls on the right hand ${ }^{14}$ could be explained by the anatomical differences in the origins of the right and left subclavian arteries in early gestation. The brachiocephalic artery, the first major branch of the aortic arch, distributes blood to both the right common carotid and subclavian arteries. ${ }^{18}$ The left subclavian artery is a branch of the dorsal aorta that is separate from the left common carotid artery and is distal to the ductus arteriosus in early gestation. If, in response to adverse stimuli, blood is redistributed to the head to preserve brain growth ${ }^{19}$ this will increase blood flow down the right subclavian artery but not down the left. Thus whorls on either hand may be a consequence of pathological processes such as in Turner's syndrome or rubella, whereas whorls on the right hand may result from selective preservation of brain growth.

The association between fingertip whorls and adult blood pressure suggests that in utero determinants of blood pressure act in early gestation. In support of this, a recent study showed that babies who are thin at birth, having a low ponderal index, had faster fetal heart rates at 18 weeks' gestation..$^{20}$ Little is known about the time when the length of the hand in relation to its breadth is established. The atd angle, which reflects the shape of the palm of the hand, is unrelated to adult height, suggesting that the angle is established in utero rather than during early childhood. The association between narrow palmar atd angle and large head size at birth 
without proportionate increase in length may reflect adverse influences in late gestation..$^{21}$

Our findings are further evidence for the in utero origin of raised adult blood pressure. Fingertip whorls and a narrow palmar angle are indelible markers of impaired fetal development at different stages in pregnancy. Both are associated with high blood pressure in adult life.

We thank Mrs F Foden and the medical records staff at Sharoe Green Hospital, who preserved the records and allowed us to use them; Lancashire Family Practitioner Committee and general practitioners throughout the county; staff at the NHS central register, Southport, who traced the subjects; Mr W Ervin, deputy head of branch, Scotland Yard, for invaluable help; and Mr Graham Wield for computing.

1 Barker DJP, Bull AR, Osmond C, Simmonds SJ. Fetal and placental size and risk of hypertension in adult life. $B M \mathcal{J}^{\gamma} 1990 ; 301: 259-62$.

2 Barker DJP, Meade TW, Fall CHD, Lee A, Osmond C, Phipps K, Stirling Y. Relation of fetal and infant growth to plasma fibrinogen and factor VII concentrations in adult life. $B M$ I $^{1992 ; 304: 148-52}$.

3 Barker DJP, Osmond C, Golding J, Kuh D, Wadsworth MEJ. Growth in utero, blood pressure in childhood and adult life, and mortality from cardiovascular disease. $B M \mathcal{F}^{1989}$;298:564-7.

4 Law CM, Barker DJP, Bull AR, Osmond C. Maternal and fetal influences on blood pressure. Arch Dis Child 1991;66:1291-5.

5 Barker DIP, Godfrey KM, Bull AR, Osmond C. The relation of fetal length, ponderal index and head circumference to blood pressure and the risk of hypertension in adult life. Paediatr Perinat Epidemiol 1992;6:35-44.
6 Mulvihill J, Smith DW. The genesis of dermatoglyphics. If Pediatr 1969;75: 579-89.

7 Lacroix B, Wolff-Quenot M-J, Haffen K. Early human hand morphology: an estimation of fetal age. Early Hum Devel 1984;9:127-36.

8 Penrose LS. Medical significance of finger-prints and related phenomena. BMF 1968;ii:321-5.

9 Reed T, Uchida IS, Norton JA, Christian JC. Comparisons of dermatoglyphic patterns in monochorionic and dichorionic monozygotic twins. Am f Hum Genet 1978;30:383-91.

10 Purvis-Smith SG. Dermatoglyphics in adults with congenital rubella. Lancet 1968;ii:141-3.

11 Jain PK, Sharma BK, Mathur BD. Dermatoglyphics in essential hypertension. f Assoc Physicians India 1984;32:335-7.

12 Pursnani ML, Elhence GP, Tibrewala L. Palmar dermatoglyphics in essential hypertension. Indian Heart f 1989;41:119-22.

13 Rashad MN; Mi MP. Dermatoglyphic traits in patients with cardiovascular disorders. Am $\mathcal{Y}$ Phys Anthropol 1975;42:281-3.

14 Cherrill FR. The fingerprint system at Scotland Yard. London: HMSO, 1954

15 Dawes GS, Borruto F, Zacutti A, Zacutti A Jr. Fetal autonomy and adaptation. Chichester: Wiley, 1990:27.

16 Kinmonth JB, Negus D. Arteriovenous fistula in the management of lower limb discrepancy. $¥$ Cardiovasc Surg (Torino) 1974;15:447-53.

17 Young AE. Maldevelopments of the vascular system: clinical conundrums. In: Nugent J, O'Connor M, eds. Development of the vascular system. London: Pitman, 1983:222-43. (Ciba Foundation Symposium No 100.)

18 Barry A. The aortic arch derivatives in the human adult. Anat Rec 1951;111:

19 Rudolph AM. The fetal circulation and its response to stress. I Dev Physiol 1984;6:11-9.

20 Robinson SM, Wheeler T, Hayes MC, Barker DJP, Osmond C. Fetal heart rate and intrauterine growth. Br F Obstet Gynaecol 1991;98:1223-7.

21 Barker DJP, Gluckman PD, Godfrey KM, Harding J, Owens JA, Robinson JS. Fetal nutrition and cardiovascular disease in adult life. Lancet 1993;341: J38-41.

(Accepted 3 Fune 1993)
Cardiac Department,

Aberdeen

Jacqueline Adams, research registrar

Roger Trent, research

registrar

Medicines Assessment Research Unit, University of Aberdeen, Foresterhill, Aberdeen AB9 2ZD

John Rawles, honorary senior lecturer

Members of the GREAT

Group are listed at the end of this report.

Correspondence to:

Dr Rawles.

BMY 1993;307:409-13

\title{
Earliest electrocardiographic evidence of myocardial infarction: implications for thrombolytic treatment
}

\author{
Jacqueline Adams, Roger Trent, John Rawles on behalf of the GREAT Group
}

\section{Abstract}

Objectives-To determine the incidence of the earliest electrocardiographic changes in patients with suspected myocardial infarction and their sensitivity and specificity for predicting the final diagnosis of acute myocardial infarction.

Design-Retrospective study of paired electrocardiograms recorded at home and on admission to hospital.

Setting-29 rural practices in Grampian and teaching hospitals in Aberdeen.

Patients-137 patients participating in the early anistreplase trial in the Grampian region, who received placebo at home and for whom paired electrocardiograms were available.

Main outcome measures-Classified electrocardiographic abnormalities and diagnosis at discharge.

Results-Electrocardiograms were recorded immediately before injection of placebo at home and anistreplase in hospital at median times of 110 and 240 minutes after the onset of symptoms. Definite or probable myocardial infarction was later confirmed in $93(68 \%)$ patients. Of these, $66(71 \%)$ had the same findings on both electrocardiograms of either ST elevation, bundle branch block, or a non-specific abnormality, while $27(29 \%)$ showed a major change of classification between home and hospital recordings; $21(23 \%)$ had ST elevation or bundle branch block on only one of the paired recordings. Although ST elevation was the commonest abnormality in the 93 patients with myocardial infarction, in only 51 was it recorded at home (sensitivity 55\%) and in 49 on admission (sensitivity $53 \%$ ). Of 57 patients with ST elevation at home, six did not have infarction (specificity 86\%), while of 51 with ST elevation on admission, two did not have infarction (specificity 95\%).

Conclusions-Elevation of the ST segment is a transient electrocardiographic abnormality that has high specificity but low sensitivity for predicting the diagnosis of acute myocardial infarction; it is an unsatisfactory precondition for giving thrombolytic treatment to patients with suspected acute myocardial infarction.

\section{Introduction}

It is now generally accepted that patients with acute myocardial infarction should receive thrombolytic treatment, provided that they present sufficiently early and there are no contraindications. Several clinical trials ${ }^{1-3}$ support the experimental evidence ${ }^{45}$ that such treatment should be given as soon as possible after the onset of infarction. As thrombolytic treatment has the potential to cause serious adverse events, cerebral haemorrhage being the most feared, it is considered important to establish the diagnosis of myocardial infarction rapidly so that only those patients who might benefit are exposed to the risks of treatment.

The use of an electrocardiograph remains the quickest, simplest, and most reliable method of diagnosing myocardial infarction. ${ }^{6}$ There are, however, varying estimates of the specificity of electrocardiographic abnormalities in patients with chest pain, ${ }^{7-10}$ and little work has been published on the very earliest changes and how these evolve in acute myocardial infarction.

The early anistreplase trial in the Grampian region ${ }^{3}$ was a randomised, double blind, parallel group trial of anistreplase, given either at home by general practitioners or later in hospital. The purpose of the trial was to assess the feasibility, safety, and efficacy of domiciliary thrombolysis by general practitioners. Provided that there were no contraindications to thrombolytic treatment, patients were entered into the trial if there was strong clinical suspicion of acute myocardial infarction when they were seen by their general practitioners within four hours after onset of symp- 